\title{
The role of a psychosis workshop in general psychiatric training
}

\author{
Antony Garelick and Richard Lucas
}

\begin{abstract}
A poychoets workshop and its clinicat role are presented. The workshop's mods of operation uttiling baik poychootynamic concepts is described with related clinicel mustrations. The velus of the workshop in implementing Colloge guidelines for general profocitonal poychiatile troining and the integration of poychotherapoutic skllis into peychiatilic practice is discusised.
\end{abstract}

Guidelines from the College stress the need to integrate psychotherapeutic skills into general psychiatric training, not only for the trainees' benefit but also to provide support for other mental health workers. The guidelines (Grant et al, 1993) state: "It is important that psychotherapy skills are seen as a core element of psychlatric practice, not in opposition to psychopharmacological approaches. The involvement of general psychiatrists in psychotherapeutic training enhances this".

A psychosis workshop is an effective way to implement this College recommendation. For a number of years a consultant psychotherapist (AG) and a consultant general psychiatrist (RL) have jointly run fortnightly workshops at Claybury Hospital. The mode of functioning of the workshop is described, together with related clinical illustrations.

\section{Structure of the workshop}

Claybury Hospital is a large mental hospital that is on the point of closure. Issues of setting up district-based services and the move to community care predominate (Carson et al, 1989). Most patients presented at the psychosis workshop therefore suffer from chronic schizophrenia, with the related problem of moving from hospital into the community. Those with seemingly unmanageable behaviour are presented at the workshop.

The workshop meets in the quiet atmosphere of a seminar room in the Psychotherapy Department. Psychiatrists, junior doctors, hospital and community-based nurses, social workers, occupational therapists and psychologists attend, as well as members of the Psychotherapy Department.
A junior doctor usually presents a case that is causing problems in management. A full psychiatric history is given, followed by a description of the current difficulties. Other professionals involved in supporting the management programme such as the community nurse and the psychologist, contribute to the presentation.

Before presenting illustrative examples, some of the theoretical concepts utilised within this workshop are described.

\section{Basic concept.}

Just as there is a need for careful consideration of the technical issues related to individual psychotherapy assessments (Garelick, 1994), consideration is needed on how to create space for thinking about psychotic patients and their environment.

Working with severely psychotic patients imposes particular strains on the staff and relatives, and one needs to be sensittve to these issues (Lucas, 1993). In this respect, Bion's (1967) analytic understanding of the mental mechanisms in the psychotic patient has proved particularly helpful. The psychotic part of the personality is intolerant of frustration and psychic pain. It seeks relief by getting rid of its perceptions and its capacity to think through the use of projection and splitting. This not only gives rise to hallucinations and delusions, but difficulties and disturbing affects are also concretely projected into the staff (Searles, 1965). In addition the boundary between the inner world and outer reality becomes blurred. Staff who work day to day with such patients are inevitably affected by these unconsclous projective processes. The result of these projections is to create pressure on the staff to act to relieve the tension.

Theoretically and clinically, it is important for professionals to understand the analytic concept of projective identification (a fantasy whereby parts of the self are located in another person who then represents these split-off parts) and the need to contain and metabolise the projections, rather than act them out (Segal, 1964). Recognition of this need enables these actions to be metabolised into thoughts. It is the ability to 
create the space for thinking, in Bion's terminology, to function as a container (a mental structure able to hold affects and the precursors of thought) that enables thinking to be substituted for evasion of thought by action.

Patients, in their dependency, endow doctors with special therapeutic powers. Psychotic patients, more than any others, engender an atmosphere of dependency. This may push the doctor to act out this role, for example, increasing the dose of medication whenever there is a disturbance, with the belief that he should always have an answer. These problems are compounded by the psychotic patient's capacity, having projected his difficulties, to then deny and rationalise, seducing staff into underrating the problem.

In psychotic patients, the degree of projection and the intensity of the attacks on the staffs capacity to think and the concreteness of their communication often overwhelm the staff's ability to think. Thinking therefore has to be done away from the patient.

With a patient with chronic schizophrenia, there is also a need to think longitudinally, appreciating that future development is slow and takes place over long periods of time. The first clinical example particularly highlights this point.

\section{Clinical examples}

Case 1

Mr A, a 51-year-old patient with chronic schizophrenia, was an only child with reported disturbed behaviour throughout his schooling. By his early twentles he was already becoming chronically hospitalised.

Over the years he had been nursed with some difficulty, mainly on an open ward. Periodically, if he did not get his own way, he would become aggresstve, claiming he was the Messiah or Jesus Christ and would then need a pertod on the locked ward to settle down again.

A new group home had been planned to accommodate patients with chronic schizophrenia previously on long-stay wards and $\mathrm{Mr}$ A was placed in this setting. At first, a decision was made to have a separate office within the group home for the nurses who were there during the day. The planning team then decided that it was wrong to have such a room, from which the residents might feel excluded. It would make it more like a ward than a home. So the room was filled by another reprovision patient. Initially, the staff played a leading role in running the group home but the aim was gradually to turn it into a self-sufficient residence in which patients would be expected to look after themselves.

Because the staff members were left with no private room in which to discuss the patients, they had to resort to holding their meetings on the upstairs landing. In response, $\mathrm{Mr} A$ became increasingly difficult. He would not tolerate hearing staff talking together about him, so they had to resort to whispering on the landing. Finally one day, during their meeting. Mr A became furious, shouted that he was the Messiah and assaulted a young member of the nursing staff. He had to be re-admitted to hospital.

\section{Comment}

In the discussion in the psychosis workshop the dominant themes brought up by the staff were the lack of an office, the intimidating nature of the patient and a sense of paralysis. Several interesting points emerged in the workshop discussion.

First, one cannot respond to problems of reprovision for chronic psychotic patients by thinking solely in terms of ordinary sensittvities. There is specific psychopathology which it is risky to ignore. Clearly, the patient's envious feelings, aroused by exclusion and separateness, remained as rife now as when recorded at the first interview, when he sat in the doctor's chair and said "Im the boss". His toleration of frustration (Oedipal and otherwise) was minimal and led to megalomanic outbursts like "I am the Messiah".

Second, Mr A demanded that any object which provoked his envy must be removed or he would attack it. The patient uses this process of psychotic rationalisation as a solution to his problems. The power and seductiveness of this type of thinking resulted in the planning team succumbing to a similar way of thinking. By removing the office they thought they had removed the cause of frustration, namely the patient's feeling of being excluded by the staff who symbolically represent parental figures. The truth is that, like parents who need the privacy of their own bedroom, the staff need their own room. away from overhearing patients in order to function. Similarly patients like Mr A need to be protected from scenes arousing unbearable envy.

\section{Case 2}

This case focuses on the requirements needed to prevent re-hospitalisation.

Mr B is a 23-year-old single man, with a sixyear history of schizophrenia, who was exhibiting disturbed behaviour in a group home. He was presented by the Rehabilitation Unit registrar with contributions from other members of the team involved in $\mathrm{Mr}$ B's care.

He had been an in-patient on the rehabilitation ward but had recently moved into a complex of group homes in the community.

The patient first presented six years previously. hearing the voices of God and the Devil telling him to kill someone. After treatment in hospital, he 
settled down and returned home. A year later, he was re-admitted, laughing inappropriately with bizarre behaviour, having thrown a brick through the window of a shop.

He again settled with hospital treatment and returned home. Finally, he was re-admitted a year later, having tried to strangle his mother and wandering at large brandishing a knife. This time, his family felt unable to have him back home again and, on discharge from hospital he was moved to the group home complex.

Mr B was the oldest of several siblings from a London family that originated in Ireland. His father died a year after he had moved into the group home. His mother had always dominated the family. She was sald to have a diagnosis of schizophrenia. On one occasion when he absconded home without medication, she responded by giving him her own trifluoperazine tablets.

His mother constantly undermined the group home staff, always wanting his medication changed and complaining that he was not improving. When the registrar drew attention to her attitude, he became the target of a written complaint to the management. Everyone felt defeated by her. The psychologist tried family therapy but she so dominated the proceedings that progress was impossible. Interestingly, the patient appeared to be quite insightful. He offered to make his mother a cup of tea to calm her nerves. When she refused, he left the family therapy to go and make himself a cup of tea to calm his own nerves.

Mr B had attended a group run by the occupational therapist for a year. He also participated in an art therapy group, usually copying book covers and showed good skills. However, a few months prior to the workshop presentation, his mental state deteriorated. He stopped attending the group and painting. He became withdrawn and uncommunicattve, cold in affect and irritable in manner. On one occasion, when another withdrawn resident would not reply to his asking what was on television, he threw a heavy paper weight through the window which narrowly missed a pedestrian.

\section{Comment}

In the psychosis workshop, we tried to explore and clarify the issues. Mr $B$ now appeared to return to his most cold, unresponstve and alarming state, although for a time he had been different, participating in activities. Another source of puzzlement was that the patient recently had taken, without warning, to going off home and then returning to the group home. It was considered that further work with the mother was impossible. She rigidly controlled the family's attitudes.
The workshop seemed to reach an impasse and struggled to find a way to gain some understanding of this patient. In the ensuing discussion it emerged that the purchasers expected the patients to progress from the rehabilitation homes to more independent living. This pressure was transmitted through the various layers of management to the staff who were caring for this patient. The planners of the new service were concerned about patients getting 'stuck' in the group homes. Their stated concern was the danger that they would be replacing hospital institutionalisation with community institutionalisation.

It emerged that $\mathrm{Mr}$ B's stopping attending groups and painting classes coincided with mention of the need to move on. AG suggested to maintain containment. RL mentioned how in his psychiatric day hospital there were some longterm patients and that this placement was the optimum niche for them. If one tried to move them, they would relapse. His concern was to help staff not to try to do more than was realistic for these patients and therefore accept their fraglity. Thus the problem became clear. The purchasers and providers were keen to actively move the patients on. The patient had become disturbed by the introduction of uncertainty about his future.

The workshop was then able to support the staff with a more realistic perspective. The staff members needed to realise that they actually had been doing a good job, but the patient needed the security of knowing that the staff would not act inappropriately and move him on prematurely. He needed to be spoken with about this so that he could realise that the staff understood his anxiety and needs. At the same time, the staff had to accept that the mother behaved as she did in order to maintain her own precarious equilibrium. They needed to absorb her criticism thus deflecting it from the patient.

\section{Comments}

The two examples illustrate how a psychosis workshop allows clinical problems to be explored and reflected upon from a distance. It is similar to the model, in an individual psychotherapy case, where the trainee therapist brings along the therapeutic diad, the patient and himself, for review with the aim of achieving a greater depth of understanding.

The occurrence of similar patterns of interaction at different organisation levels in a psychiatric hospital is known as 'parallel process' (Stanton \& Schwartz, 1954; Voorhoeve \& Van Putte, 1994).

Mr A demonstrated that rationalisation and denial are mechanisms not only confined to the 
patient, these processes may operate in parallel in various tiers of a mental health organisation.

The planners' and Mr A's reaction about the staff office illustrates the subtlety of projective identificatory processes, that is the method by which the patient's own thinking became located externally in the planning staff. The seductive appeal of such thinking can lead to underestimating the morbidity and needs of such patients.

Discussing such problems in the workshop exposed the degree of disavowal of feelings that could occur in a psychotic patient. Mr B appeared cold and affectless, punctuated by episodic outbursts. The feelings of helplessness and hopelessness engendered by the patient in the staff resulted in the belief that the patient was unreachable. Identification of the counter-transference in the workshop enabled staff to recognise that they were experlencing his profound diffculty in being able to influence either his mother or the world around him.

The psychosis workshop enables such issues to be identified and can lead to a more informed dialogue about appropriate provision for such patients. It can also bring life and hope back into clinical situations which have reached a therapeutic impasse.

The clinical examples also demonstrate the emotional pressure such patients generate. There is a continual demand that something must be done. In such situations there is a constant tension between being with (emotionally available) and doing to (a more active therapeutic approach) (Wolff, 1971; Bateman, 1995). The workshop creates an opportunity to explore clinical and related institutional issues and facilitates identification of the predominant mental mechanisms. It enables the critical therapeutic balance to be preserved, the capacity to maintain an appropriate therapeutic space being a constant clinical challenge.

The joint psychosis workshop is an effective way of achieving College recommendations and demonstrates the contribution that psychoanaly- tically informed thinking can bring to general psychiatry. It raises for further consideration the question of whether the joint workshop model might have a place in other areas of training, such as in child and forensic psychiatry.

\section{Acknowiedgements}

We would like to thank Dr A. Soutter, then Senior Psychotherapy Registrar, and Mr K. Navaratnam, Psychotherapy Clinic Co-ordinator Psychotherapist, for help in the running of the Psychosis Workshop.

\section{References}

BATEMAN, A. (1995) The treatment of borderiline patients in a day hospital setting. Psychoanalytic Psychotherapy. 9. 3-16.

BION, W. R. (1967) Second Thoughts. London: Helnemann.

CARSON, J., SHAw, L. \& WuLs, W. (1989) Which patients first? A study from the closure of a large peychiatric hospital. Health Trends, 4, 117-120.

GAREuCK, A. (1994) Psychotherapy assessment, theory and practice. Psychoanalytic Psychotherapy, 8, 101-116.

Grant, S., Holmis, J. \& WATSON, J. (1993) Guidelines for psychotherapy training as a part of general professional psychiatric training. Psychiatric Bulletin, 17, 695-698.

LucAs, R. (1993) The psychotic wavelength. Psychoanalytic Psychotherapy, 7, 15-24.

SEnRIES, H. F. (1965) Collected Papers on Schizophrenia and Related Subjects. New York: International Untversities Press.

SEGAL, H. (1964) Introduction to the Work of Melanie Kletn. London: Heinemann.

STANTON, A. B. \& SCHWARTZ, S. (1954) The Mental Hospital: a Study of Institutional Partictpation in Psychiatric Illness and Treatment. New York: Basic Books.

VOORHOEVE, J. N. \& VAN PUTTE, F. C. A. (1994) 'Parallel processes' in supervision when working with peychotic patients. Group Analysis, 27, $459-466$.

Wour, H. H. (1971) The therapeutic and developmental functions of peychotherapy. British Joumal of Medical Psychology, 4., 117-130.

Antony Garelick, Consultant Psychotherapist, and Richard Lucas, Consultant Psychiatrist, Claybury Hospital, Woodford Bridge, Essex IG8 8BY 